\title{
Evoked Potential as a Pain Evaluation Index for Neonatal Procedural Pain
}

Yui Shiroshita $^{1^{*}}$, Hikari Kirimoto ${ }^{1}$, Kei Nakagawa ${ }^{1}$, Hiroko Uematsu ${ }^{2}$ and Ikuko Sobue ${ }^{1}$

${ }^{1}$ Division of Integrated Health Sciences, Graduate School of Biomedical and Health Sciences, Hiroshima University, Hiroshima, Japan

${ }^{2}$ School of Nursing, University of Human Environments, Aichi, Japan

\section{Abstract}

Frequent pain has short- and long-term negative influences on the development of the brain and nerves and cognition, motion, and behavior of neonates. Neonates staying in the Neonatal Intensive Care Unit frequently receive painful procedures many times a day. Heel lance is one of the most frequently performed painful procedures for blood sampling, but the pain of heel lance has been not sufficiently managed for a long time. Due to the lack of the analgesic effect and safety of pharmacological intervention, the pain relief for neonatal heel lance is being searched for in diverse combinations of non-pharmacological interventions. To develop pain relief for the heel lance, the Premature Infant Pain Profile (PIPP) comprised of a mixture of physiological and behavioral indices is frequently used as a pain evaluation index, but several problems of PIPP have been pointed out with regard to neonatal pain evaluation, and pain evaluation using PIPP alone interferes with the development of pain relief for neonatal heel lance. Recently, evoked potentials (EP) after heel lance have been attracting attention as an index of evaluating pain objectively and quantitatively for neonates unable to express pain with words. EP detects more sharply pain stimulation and may enable continuous evaluation of neonatal pain along with growth and development. The development of EP-based pain evaluation promotes the development of pain relief for neonatal heel lance.

\section{Publication History:}

Received: March 23, 2020

Accepted: May 03, 2020

Published: May 05, 2020

\section{Keywords:}

Heel lance, Evoked potential, Pain evaluation index, Infant, Pain

\section{Introduction}

Neonates staying in the Neonatal Intensive Care Unit (NICU) frequently receive procedures accompanied by pain for examination and therapy. Pain that neonates receive in the period of complex and rapid brain development have short- and long-term negative influences on the development of the brain and nerves and cognition, motion, and behavior of neonates. Heel lance is a blood sampling procedure and it is the most frequent and common painful procedure applied to neonates staying in the NICU. Therefore, the development of pain relief for the pain of neonatal heel lance has been attempted for a long time, but no conclusion has been reached with regard to safe and effective pain relief for neonatal heel lance. One of its reasons is problems with pain evaluation due to a lack of pain expression with words by neonates. In this report, trends of pain evaluation indexes used in neonates and the relief of the pain of neonatal heel lance are discussed and then benefits and future prospects of evoked potentials (EP) recently attracting attention as a neonatal pain evaluation index are introduced.

\section{Subsequent Influence of Pain in Neonates}

Pain detected by peripheral nociceptors is transmitted to the cerebral cortex via the spinal cord, brainstem, and thalamus $[1,2]$. At the same time, pain transmission from the spinal cord to the brain is inhibited by descending inhibitory controls, adjusting pain [1] Development of this pain transmission and pain modulation rapidly starts at 22 weeks of gestation and mature 2 months after birth in healthy full-term infants [1-5].

Neonates staying in the NICU, especially preterm infants born earlier than 37 weeks of gestation, receive painful procedures 7.517.3 times a day for examination and treatment in this complex and rapid developmental period of the pain transmission pathway $[6,7]$, so that preterm infants are exposed to the risks for poor early neurodevelopment, developmental disorder of the brain, and delay in postnatal growth $[1,8]$. The nerve activity level is high during heel lance in preterm infants who received intensive care for at least 40 days or special treatment compared with that in age-matched term infants who did not stay in the NICU [9]. In addition, in a cohort study involving preterm infants, frequent pain was associated with lower body weight and head circumference at 32 weeks [10] and a reduction of the white matter and subcortical gray matter at the termequivalent age [11] even though other medical confounding factors were adjusted.

Repeated pain in the neonatal period has a long-term negative influence. In preterm infants, poorer cognition and motor function in infancy [12], a reduction of Full Scale IQ (FSIQ) at school age [13], and a reduction of the cognitive score in late adolescence [14] have been reported even though other medical confounding factors were adjusted for (after comprehensively adjusting for multiple clinical factors). Moreover, internalizing behaviors, such as depression and anxiety, were clearly noted in infancy in preterm infants compared with full-term infants even though other medical confounding factors were adjusted for [15], and it continues to school age, late adolescence, and young adulthood [16-20].

Painful procedures in the NICU include heel lance, blood sampling, arterial puncture, lumbar puncture, and placement and intramuscular injection, and heel lance is one of the most frequently performed painful procedures [21]. Of the painful procedures performed 3,605 times in total in 55 neonates who stayed in the NICU for 28 days or longer, heel lance accounted for $71 \%$ [22]. However, the pain of the most frequently performed heel lance in the NICU is not sufficiently managed. In Italy, $30 \%$ of 140 medical workers of 5 NICUs ( 89 nurses and 51 physicians) answered that no intervention is performed for heel lance [23].

"Corresponding Author: Yui Shiroshita, Division of Integrated Health Sciences, Graduate School of Biomedical and Health Sciences, Hiroshima University, 1-23, Kasumi, Minami-ku, Hiroshima 734-8553, Japan; Tel: 81-82-257-5371; E-mail: d176710@hiroshima-u.ac.jp

Citation: Shiroshita Y, Kirimoto H, Nakagawa K, Uematsu H, Sobue I (2020) Validity of the Dialog Preference Scale for Nurses' Communication with Older People in Japan. Int J Nurs Clin Pract 7: 323. doi: https://doi.org/10.15344/23944978/2020/323

Copyright: (C) 2020 Shiroshita. This is an open-access article distributed under the terms of the Creative Commons Attribution License, which permits unrestricted use, distribution, and reproduction in any medium, provided the original author and source are credited. 
Citation: Shiroshita Y, Kirimoto H, Nakagawa K, Uematsu H, Sobue I (2020) Validity of the Dialog Preference Scale for Nurses' Communication with Older People in Japan. Int J Nurs Clin Pract 7: 323. doi: https://doi.org/10.15344/2394-4978/2020/323

Neonates staying in the NICU cannot avoid frequent pain stimulation for treatment and examination. To prevent a negative influence on the development of the brain and nerves and cognition, motion, and behavior, it is essential to manage the pain of heel lance most frequently performed in the NICU.

\section{Pain Evaluation Index for Neonates}

For the neonatal pain assessment tool, a mixture of physiological and behavioral indices has been recommended [24,25]. Many pain evaluation indices are prepared by comprehensively mixing facial expressions (grimace), physiologic measurements (vital signs, such as heart rate and blood pressure, respiratory rate, and pulse-oximetry readings/oxygen requirement), and behavioral components (crying/ consolability or motor activity) [24].

For the pain assessment tool for acute and procedural pain in children including neonates, Premature Infant Pain Profile (PIPP) and Premature Infant Pain Profile-Revised (PIPP-R), Neonatal Infant Pain Scale (NIPS), Crying, Requires oxygen, Increased vital signs, Expression, and Sleeplessness (CRIES) (neonatal period), Distress Scale for Ventilated Newborn Infants (DSVNI) (Ventilated neonates and infants), Douleur Aigue du Nouveau-né (DAN) (neonatal period-3 months), Neonatal Facial Coding System (NFCS) (neonatal period-18 months), and Evaluation Enfant Douleur (EVENDOL) (neonatal period-6 years old) have been reported [26,27].

In many studies on pain relief for neonatal heel lance, PIPP or PIPP-R is selected for the pain evaluation index [28,29]. PIPP is comprised of 2 physiological indices (heart rate and oxygen saturation) and 3 behavior indices (brow bulge, eye squeeze, and nasolabial furrow) and the score is corrected with the gestational age and behavioral state [30]. The score varies from 0 to 21 , a score of 6 or lower represents that there is almost or completely no pain, and a score of 12 or higher represents moderate to severe pain [31]. The reliability and validity of PIPP have been demonstrated [30,32,33]. In PIPP-R, weighting by the gestational age and behavioral state in PIPP was modified $[34,35]$ and between-rater reliability [34] and construct validity [34,35] have been demonstrated.

\section{Study on Pain Relief for Heel Lance}

\section{Insufficiency of analgesic effect and adverse effect of pharmacological intervention}

It has been reported that no pharmacological intervention exhibited an analgesic effect for neonatal heel lance but adverse effects developed.

In a study on heel lance involving 42 neonates, no significant difference was noted in DAN between the morphine and placebo groups (5\% glucose dextrose infusions) [36]. In a study on heel lance involving 30 neonates, morphine did not exhibit an analgesic effect on PIPP-R and morphine induced a reduction of oxygen saturation and prolongation of bradycardia time [37].

In a study on heel lance involving 72 neonates, there was no significant difference in PIPP between the paracetamol and placebo (cherry elixir) groups [38]. In a study on heel lance involving 75 neonates, no difference was noted in the facial action or cry scores between the paracetamol and placebo (sterile water) groups, showing no analgesic effect [39].
In a study on heel lance involving 106 neonates, no significant difference was noted in PIPP between the Lidocaine-Prilocaine (EMLA) cream and placebo cream (Glaxal) groups [40]. Similarly, no difference was noted in pain cry between the Lidocaine-Prilocaine (EMLA) cream and placebo cream groups, showing no analgesic effect, in a study on heel lance involving 112 neonates [41]. In 8 studies investigating the analgesic effect of EMLA cream on invasive treatment including heel lance in neonates, no sufficient evidence for the efficacy of the analgesic was acquired because of insufficiency of the sample size and diversity of the measurement index [42].

Accordingly, because of the lack of the analgesic effect and safety of pharmacological intervention, development of pain relief by non-pharmacological intervention for neonatal heel lance has been promoted.

\section{Achievements and problems of non-pharmacological intervention}

The PIPP scores of oral sucrose (2.74-5.0) [29,43,44], combination of pacifiers and oral sucrose (3.0-5.7) [29,45-47], and combination of sucrose and music (3.0) [44] for the pain of neonatal heel lance were 6 or lower, but an increase in oxidative stress 48 and delay in nerve development $[49,50]$ induced by frequent administration of sucrose contained in all intervention methods have been reported.

For the pain of neonatal heel lance, the effect of pain relief by the interventions described below and combination thereof has been investigated, but the PIPP score was 6 or higher in all conditions, remaining pain: pacifiers (6.4-9.5) [45-47,51-55], facilitated tucking (3.8-9.6) [51,52,54,56-59], breast milk (3.0-9.7) [52, 60-62], swaddling (7.0-10.7) [63,64], kangaroo care (4.1-8.9) [64-67], and holding (13.3) [61].

The PIPP scores of a combination of music, pacifiers, facilitated tucking, and holding [68] and a combination of music and facilitated tucking [69] for pain of neonatal heel lance were 6 or lower (3.6-5.1) and no adverse effect was reported.

Due to the lack of the analgesic effect and safety of pharmacological intervention and adverse effect of oral sucrose, the methods showing an analgesic action on the pain of neonatal heel lance are a combination of music, pacifiers, facilitated tucking, and holding and a combination of music and facilitated tucking. At present, the effective and safe pain relief for neonatal heel lance is being searched for in diverse combinations of interventions.

\section{Appearance of Evoked Potential (EP) and Limit of Premature Infant Pain Profile (PIPP)}

The potentials evoked by pain represent cerebral cortical activity induced by pain stimulation transmitted through the peripheral nociceptor, spinal cord, brainstem, and thalamus1, 2. The 2 main types of pain sensing neurons in the skin and other peripheral tissues are myelinated $\mathrm{A} \delta$ and unmyelinated $\mathrm{C}$ nociceptor [70-72]. A $\delta$ fibers respond to rapid, pricking, and localized pain and $\mathrm{C}$ fibers respond to diffuse, burning or aching sensation [70, 73-76]. Selective stimulation of these fibers and recording EP have recently become possible. Intraepidermal electrical stimulation is a method to selectively stimulate A $\delta$ fibers.

We previously reported that EP consisted of $226.6 \pm 8.2 \mathrm{~ms}$ negative waves (N2) and $328.2 \pm 10.9$ ms positive waves (P2) by intraepidermal electrical stimulation in 18 adults (Figure1) [77], showing selective activation of A $\delta$ fibers. The values of EP parameters recorded, such 
Citation: Shiroshita Y, Kirimoto H, Nakagawa K, Uematsu H, Sobue I (2020) Validity of the Dialog Preference Scale for Nurses' Communication with Older People in Japan. Int J Nurs Clin Pract 7: 323. doi: https://doi.org/10.15344/2394-4978/2020/323

as the latency of $\mathrm{N} 2$ and $\mathrm{P} 2$, amplitudes of EP (N2-P2), and sensory threshold, were within the range of the results of our and another group's studies, which employed similar common parameters [78-82].

On the other hand, nerve transmission of pain stimulation is delayed in neonates because myelination is lacking and synaptic currents are immature $[83,84]$. The latency of the EP by heel lance in neonates (403-420 ms negative wave (N2) and 413-538 ms positive wave (P2)) is longer than that by the stimulation of $\mathrm{A} \delta$ fibers in adults [85-88], and the activation of $A \delta$ fibers by heel lance in neonates has not been clarified. However, in neonates, when compared with painless tactile stimulation, the amplitude of heel lance-EP was significantly higher, showing that the pain of heel lance is present by the EP [85-88].

Moreover, the indication of PIPP is limited to the neonatal period [30]. The pain evaluation index has to be changed with child growth, such as Face Legs Activity Cry Consolability (FLACC) [89] in infancy-childhood and Face Scale [90] in childhood and thereafter Accordingly, continuous pain evaluation with growth is difficult for many pain evaluation indices.

Therefore, pain evaluation using PIPP alone is not sufficient. Electrophysiological EP more sharply detecting pain stimulation are expected to contribute to the development of pain relief for neonates [91].

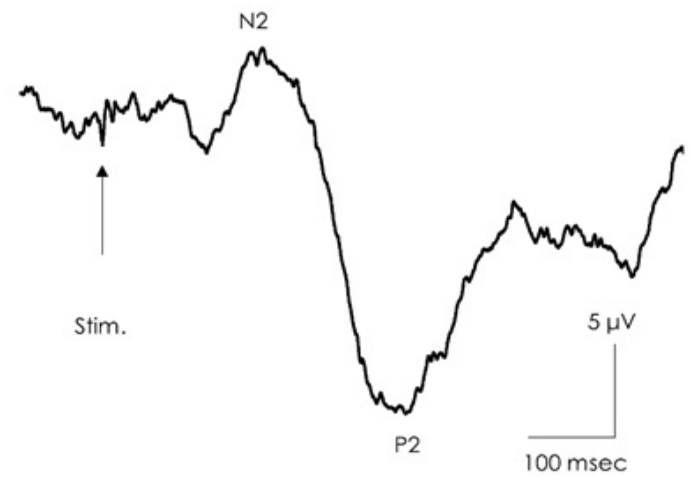

Figure 1: Grand average of intraepidermal electrical stimulation evoked potential waveforms on hand dorsum. (Created based upon date from Source: Kirimoto H, 2018 [77]).

\section{Development of EP}

To develop pain relief for heel lance for neonates unable to express pain with words, EP may serve as an index to evaluate the pain relief effect. Regarding the action of sucrose in the neonatal heel lance procedure, the PIPP score was significantly lower in the sucrose $(n=29)$ than sterile water group $(n=30)$, but there was no difference in the EP between the 2 groups [86]. This finding suggested non-effectivity of sucrose for the pain of neonatal heel lance [86]. In addition, in a study on the pain relief effect of slow tactile stimulation in neonatal heel lance, the EP after heel lance in neonates who received slow tactile stimulation was significantly smaller than that in neonates after heel lance in the control group (no touch) [92]. Regarding the EP, the pain relief effect of slow tactile stimulation during neonatal heel lance has been reported [92].

In addition, EP-based pain evaluation may enable continuous pain evaluation along with growth. Pain stimulation-induced EP have reported in the neonatal period, infancy at one year old, and at school age and thereafter. Studies on EP-based pain evaluation were performed in neonates at 35 weeks of gestation to 45 weeks of postmenstrual age at which distinguishing tactile and pain sensations is established [85-88]. Furthermore, EP similar to those induced by neonatal heel lance have been detected in a study on vaccination of 17 infants [93]. In a study in which laser stimulation was applied to healthy subjects in childhood and thereafter (7-72 years old, 237 subjects), negative and positive waves, which are pain-induced EP, were clearly detected in all subjects [94]. EP-based pain evaluation may enable continuous evaluation of neonatal pain along with growth and development.

\section{Conclusion}

Pain evaluation using PIPP is frequently employed in neonatal heel lance, but PIPP has a limit of pain detection sensitivity. EP capable of sensing low-intensity pain without judgment by a rater may serve as an index capable of evaluating pain objectively and quantitatively for neonates unable to express pain with words. The development of EP-based pain evaluation promotes the development of pain relief for neonatal heel lance.

\section{Funding}

This work was supported in part by Japan Society for the Promotion of Science (JSPS) KAKENHI Grant Numbers JP17K19818.

\section{Author's Contributions}

Yui Shiroshita were involved in all the process of this study from the conception of this study to drafting and final approval of the manuscript. Hikari Kirimoto, Kei Nakagawa, Hiroko Uematsu contributed to the writing and final approval of the manuscript. Ikuko Sobue contributed to the conception and design of the study.

\section{Competing Interests}

The authors declare that they have no competing interests.

\section{References}

1. Hatfield LA (2014) Neonatal pain: What's age got to do with it? Surg Neurol Int 5: S479-S489.

2. Basbaum AI, Fields HL (1984) Endogenous pain control systems: brainstem spinal pathways and endorphin circuitry. Annu Rev Neurosci 7: 309-338.

3. Anand KJ, Hickey PR (1987) Pain and its effects in the human neonate and fetus. N Engl J Med 317: 1321-1329.

4. Rodrigues AC, Guinsburg R (2013) Pain evaluation after a non-nociceptive stimulus in preterm infants during the first 28 days of life. Early Hum Dev 89: 75-79.

5. Vinall J, Grunau RE (2014) Impact of repeated procedural pain-related stress in infants born very preterm. Pediatr Res 75: 584-587.

6. Cruz MD, Fernandes AM, Oliveira CR (2016) Epidemiology of painful procedures performed in neonates: A systematic review of observational studies. Eur J Pain 20: 489-498.

7. Ranger M, Grunau RE (2014) Early repetitive pain in preterm infants in relation to the developing brain. Pain Manag 4: 57-67.

8. Valeri BO, Holsti L, Linhares MB (2015) Neonatal pain and developmental outcomes in children born preterm: a systematic review. Clin J Pain 31: $355-$ 362. 
Citation: Shiroshita Y, Kirimoto H, Nakagawa K, Uematsu H, Sobue I (2020) Validity of the Dialog Preference Scale for Nurses' Communication with Older People in Japan. Int J Nurs Clin Pract 7: 323. doi: https://doi.org/10.15344/2394-4978/2020/323

9. Slater R, Fabrizi L, Worley A, Meek J, Boyd S, et al. (2010) Premature infants display increased noxious-evoked neuronal activity in the brain compared to healthy age-matched term-born infants. Neuroimage 52: 583-589.

10. Vinall J, Miller SP, Chau V, Brummelte S, Synnes AR, et al. (2012) Neonatal pain in relation to postnatal growth in infants born very preterm. Pain 153 : 1374-1381.

11. Brummelte S, Grunau RE, Chau V, Poskitt KJ, Brant R, et al. (2012) Procedural pain and brain development in premature newborns. Ann Neurol 71: 385 396.

12. Grunau RE, Whitfield MF, Petrie-Thomas J, Synnes AR, Cepeda IL, et al (2009) Neonatal pain, parenting stress and interaction, in relation to cognitive and motor development at 8 and 18 months in preterm infants. Pain 143: 138-146.

13. Vinall J, Miller SP, Bjornoson BH, Fitzpatrick KP, Poskitt KJ, et al. (2014) Invasive procedures in preterm children: brain and cognitive development at school age. Pediatrics 133: 412-421.

14. Walker SM, Melbourne A, O'Reilly H, Beckmann J, Eaton-Rosen Z, et al. (2018) Somatosensory function and pain in extremely preterm young adults from the UK EPICure cohort: sex-dependent differences and impact of neonatal surgery. Br J Anaesth 121: 623-635.

15. Vinall J, Miller SP, Synnes AR, Grunau RE (2013) Parent behaviors moderate the relationship between neonatal pain and internalizing behaviors at 18 months corrected age in children born very prematurely. Pain 154: 18311839.

16. Anderson P, Doyle LW (2003) Neurobehavioral outcomes of school-age children born extremely low birth weight or very preterm in the 1990s. JAMA 289: 3264-3272.

17. Loe IM, Lee ES, Luna B, Feldman HM (2011) Behavior problems of 9-16 year old preterm children: biological, sociodemographic, and intellectual contributions. Early Hum Dev 87: 247-252.

18. Grunau RE, Whitfield MF, Fay TB (2004) Psychosocial and academic characteristics of extremely low birth weight $(<$ or $=800 \mathrm{~g})$ adolescents who are free of major impairment compared with term-born control subjects. Pediatrics 114: e725-e732.

19. Schmidt LA, Miskovic V, Boyle M, Saigal S (2010) Fronta electroencephalogram asymmetry, salivary cortisol, and internalizing behavior problems in young adults who were born at extremely low birth weight. Child Dev 81: 183-199.

20. var Baar AL, Vermaas J, Knots E, de Kleine MJ, Soons P (2009) Functioning at school age of moderately preterm children born at 32 to 36 weeks' gestational age. Pediatrics 124: 251-257.

21. Foster JP, Taylor C, Spence K (2017) Topical anaesthesia for needle-related pain in newborn infants. Cochrane Database Syst Rev 2: CD010331.

22. Harrison D, Loughnan P, Manias E, Johnston L (2009) Analgesics administered during minor painful procedures in a cohort of hospitalized infants: a prospective clinical audit. J pain 10: 715-722.

23. Bellieni CV, Tei M, Cornacchione S, Di Lucia S, Nardi V, et al. (2017) Pain perception in NICU: a pilot questionnaire. J Matern Fetal Neonatal Med 31 1921-1923.

24. Carter BS, Brunkhorst J (2017) Neonatal pain management. Semin Perinato 41: $111-116$.

25. American Academy of Pediatrics Committee on Fetus and Newborn American Academy of Pediatrics Section on Surgery; Canadian Paediatric Society Fetus and Newborn Committee, Batton DG, Barrington KJ, Wallman $C$ (2006) Prevention and management of pain in the neonate: an update. Pediatrics 118: 2231-2241.

26. Manworren RC, Stinson J (2016) Pediatric pain measurement, assessment, and evaluation. Semin Pediatr Neurol 23: 189-200.

27. Beltramini A, Milojevic K, Pateron D (2017) Pain assessment in newborns, infants, and children. Pediatr Ann 46: e387-e395.

28. Pillai Riddell RR, Racine NM, Gennis HG, Turcotte K, Uman LS, et al. (2015) Non-pharmacological management of infant and young child procedural pain. Cochrane Database Syst Rev 12: CD006275.

29. Stevens B, Yamada J, Ohlsson A, Haliburton S, Shorkey A (2016) Sucrose for analgesia in newborn infants undergoing painful procedures. Cochrane Database Syst. Rev 7: CD001069.

30. Ballantyne M, Stevens B, McAllister M, Dionne K, Jack A (1999) Validation of the premature infant pain profile in the clinical setting. Clin J Pain 15 : 297-303.
31. Stevens B, Johnston C, Petryshen P, Taddio A (1996) Premature Infant Pain Profile: development and initial validation. Clin J Pain 12: 13-22.

32. Stevens B, Johnston C, Taddio A, Gibbins S, Yamada J (2010) The premature infant pain profile: evaluation 13 years after development. Clin J Pain 26 : 813-830.

33. Ozawa M, Kanda K, Hirata M, Kusakawa I, Suzuki, C (2010) Utility of a Japanese version of the Premature Infant Pain Profile. J Jap Acad Neonat Nurs 16: 28-33

34. Gibbins S, Stevens BJ, Yamada J, Dionne K, Campbell-Yeo M, et al (2014) Validation of the premature infant pain profile-revised (PIPP-R). Early Hum Dev 90: 189-193.

35. Stevens BJ, Gibbins S, Yamada J, Dionne K, Lee G, et al. (2014) The premature infant pain profile-revised (PIPP-R): initial validation and feasibility. Clin J Pain 30: 238-243.

36. Carbajal R, Lenclen R, Jugie M, Paupe A, Barton BA, et al. (2005) Morphine does not provide adequate analgesia for acute procedural pain among preterm neonates. Pediatrics 115: 1494-1500.

37. Hartley C, Moultrie F, Hoskin A, Grenn G, Monk V, et al. (2018) Analgesic efficacy and safety of morphine in the procedural pain in premature infants (Poppi) study: randomised placebo-controlled trial. Lancet 392: 2595-2605.

38. Badiee Z, Torcan N (2009) Effects of high dose orally administered paracetamol for heel prick pain in premature infants. Saudi Med J 30: 14501453.

39. Shah V, Taddio A, Ohlsson A (1998) Randomised controlled trial of paracetamol for heel prick pain in neonates. Arch Dis Child Fetal Neonatal Ed 79: F209-F211.

40. Stevens B, Johnston C, Taddio A, Jack A, Narciso J, et al. (1999) Management of pain from heel lance with lidocaine-prilocaine (EMLA) cream: is it safe and efficacious in preterm infants? J Dev Behav Pediatr 20: 216-221.

41. Larsson BA, Jylli L, Lagercrantz H, Olsson GL (1995) Does a local anaesthetic cream (EMLA) alleviate pain from heel-lancing in neonates? Acta Anaesthesiol Scand 39: 1028-1031.

42. Foster JP, Taylor C, Spence K (2017) Topical anaesthesia for needle-related pain in newborn infants. Cochrane Database Syst Rev 2: CD010331.

43. Kumari S, Datta V, Rehan H (2017) Comparison of the Efficacy of Oral 25\% Glucose with Oral 24\% Sucrose for Pain Relief during Heel Lance in Preterm Neonates: A Double Blind Randomized Controlled Trial. J Trop Pediatr 63: 30-35.

44. Shah SR, Kadage S, Sinn J (2017) Trial of Music, Sucrose, and Combination Therapy for Pain Relief during Heel Prick Procedures in Neonates. J Pediatr 190: $153-158$

45. Angeles DM, Asmerom Y, Boskovic DS, Slater L, Bacot-Carter S, et al. (2015) Oral sucrose for heel lance enhances adenosine triphosphate use in preterm neonates with respiratory distress. SAGE Open Med 3: 2050312115611431.

46. Thakkar P, Arora K, Goyal K, Das RR, Javadekar B, et al. (2016) To evaluate and compare the efficacy of combined sucrose and non-nutritive sucking for analgesia in newborns undergoing minor painful procedure: a randomized controlled trial. J Perinatol 36: 67-70.

47. Gao H, Li M, Gao H, Xu G, Li F, et al. (2018) Effect of non-nutritive sucking and sucrose alone and in combination for repeated procedural pain in preterm infants: A randomized controlled trial. Int J Nurs Stud 83: 25-33.

48. Asmerom Y, Slater L, Boskovic DS, Bahjri K, Holden MS, et al. (2013) Ora sucrose for heel lance increases adenosine triphosphate use and oxidative stress in preterm neonates. J Pediatr 163: 29-35.

49. Schneider J, Duerden EG, Guo T, Ng K, Hagmann P, et al. (2018) Procedura pain and oral glucose in preterm neonates: brain development and sexspecific effects. Pain 159: 515-525.

50. Walker SM (2019) Long-term effects of neonatal pain. Semin Fetal Neonatal Med 24: 101005.

51. Campbell-Yeo M (2019) Combining facilitated tucking and non-nutritive sucking appears to promote greater regulation for preterm neonates following heel lance, but does not provide effective pain relief. Evid Based Nurs 22: 19.

52. Peng HF, Yin T, Yang L, Wang C, Chang YC, et al. (2018) Non-nutritive sucking, oral breast milk, and facilitated tucking relieve preterm infant pain during heel-stick procedures: A prospective, randomized controlled trial. Int J Nurs Stud 77: 162-170.

53. Liaw JJ, Yang L, Ti Y, Blackburn ST, Chang YC, et al. (2010) Non-nutritive sucking relieves pain for preterm infants during heel stick procedures in Taiwan. J Clin Nurs 19: 2741-2751. 
Citation: Shiroshita Y, Kirimoto H, Nakagawa K, Uematsu H, Sobue I (2020) Validity of the Dialog Preference Scale for Nurses' Communication with Older People in Japan. Int J Nurs Clin Pract 7: 323. doi: https://doi.org/10.15344/2394-4978/2020/323

54. Liaw JJ, Yang L, Katherine Wang KW, Chen CM, Chang YC et al. (2012) Nonnutritive sucking and facilitated tucking relieve preterm infant pain during heel-stick procedures: a prospective, randomised controlled crossover trial. Int J Nurs Stud 49: 300-309.

55. Stevens B, Johnston C, Franck L, Petryshen P, Jack A, et al. (1999) The efficacy of developmentally sensitive interventions and sucrose for relieving procedural pain in very low birth weight neonates. Nurs Res 48: 35-43.

56. Perroteau A, Nanquette MC, Rousseau A, Renolleau S, Bérard L, et al. (2018) Efficacy of facilitated tucking combined with non-nutritive sucking on very preterm infants' pain during the heel-stick procedure: A randomized controlled trial. Int J Nurs Stud 86: 29-35.

57. Davari S, Borimnejad L, Khosravi S, Haghani H (2019) The effect of the facilitated tucking position on pain intensity during heel stick blood sampling in premature infants: a surprising result. J Matern Fetal Neonatal Med 32: 3427-3430.

58. Axelin A, Salantera S, Kirjavainen J, Lehtonen L (2009) Oral glucose and parental holding preferable to opioid in pain management in preterm infants. Clin J Pain 25: 138-145.

59. Sundaram B, Shrivastava S, Pandian JS, Singh VP (2013) Facilitated tucking on pain in pre-term newborns during neonatal intensive care: a single blinded randomized controlled cross-over pilot trial. J Pediatr Rehabil Med 6: $19-27$

60. Hsieh KH, Chen SJ, Tsao PC, Wang CC, Huang CF, et al. (2018) The analgesic effect of non-pharmacological interventions to reduce procedural pain in preterm neonates. Pediatr Neonatol 59: 71-76.

61. Obeidat HM, Shuriquie MA (2015) Effect of Breast-Feeding and Materna Holding in Relieving Painful Responses in Full-Term Neonates: A Randomized Clinical Trial. J Perinat Neonatal Nurs 29: 248-254.

62. Codipietro L, Ceccarelli M, Ponzone A (2008) Breastfeeding or oral sucrose solution in term neonates receiving heel lance: a randomized, controlled trial. Pediatrics 122: e716-e721.

63. Ho LP, Ho SS, Leung DY, So WK, Chan CW (2016) A feasibility and efficacy randomised controlled trial of swaddling for controlling procedural pain in preterm infants. J Clin Nurs 25: 472-482.

64. Johnston CC, Filion F, Campbell-Yeo M, Goulet C, Bell L, et al. (2008) Kangaroo mother care diminishes pain from heel lance in very preterm neonates: a crossover trial. BMC Pediatr 8: 13.

65. Shukla VV, Bansal S, Nimbalkar A (2018) Pain Control Interventions in Preterm Neonates: A Randomized Controlled Trial. Indian Pediatr 55: 292 296.

66. Seo YS, Lee J, Ahn HY (2016) Effects of Kangaroo Care on Neonatal Pain in South Korea. J Trop Pediatr 62: 246-249.

67. Choudhary M, Dogiyal H, Sharma D, Datt Gupta B, Madabhavi I, et al. (2016) To study the effect of Kangaroo Mother Care on pain response in preterm neonates and to determine the behavioral and physiological responses to painful stimuli in preterm neonates: a study from western Rajasthan. Matern Fetal Neonatal Med 29: 826-831.

68. Uematsu H, Sobue I (2018) Effect of music (Brahms lullaby) and nonnutritive sucking on heel lance in preterm infants: a randomized controlled crossover trial. Paediatr Child Health 24: e33-e39.

69. Cavaiuolo C, Casani A, Di Manso G, Orfeo L (2015) Effect of Mozart music on heel prick pain in preterm infants: a pilot randomized controlled trial. Pediatr Neonat Individual Med 4: e040109.

70. Tzabazis AZ, Klukinov M, Crottaz-Herbette S, Nemenov MI, Angst MS, et al. (2011) Selective nociceptor activation in volunteers by infrared diode laser. Mol Pain 7: 18

71. Zotterman $Y$ (1939) Touch, pain and tickling: an electro-physiological investigation on cutaneous sensory nerves. J Physiol 95: 1-28.

72. Burgess PR, Perl ER (1967) Myelinated afferent fibres responding specifically to noxious stimulation of the skin. J Physiol 190: 541-562.

73. Torebjörk HE, Hallin RG (1973) Perceptual changes accompanying controlled preferential blocking of $A$ and $C$ fibre responses in intact human skin nerves. Exp Brain Res 16: 321-332.

74. Hallin RG, Torebjörk HE (1973) Electrically induced A and C fibre responses in intact human skin nerves. Exp Brain Res 16: 309-320.

75. Price DD, Barrell JJ, Gracely RH (1980) A psychophysical analysis of experimential factors that selectively influence the affective dimension of pain. Pain 8: 137-149.
76. Adriaensen H, Gybels J, Handwerker HO, Van Hees J (1983) Response properties of thin myelinated (A-delta) fibers in human skin nerves. J Neurophysiol 49: 111-122.

77. Kirimoto H, Tamaki H, Otsuru N, Yamashiro K, Onishi H, et al. (2018) Transcranial static magnetic field stimulation over the primary motor cortex induces plastic changes in cortical nociceptive processing. Front Hum Neurosci 12: 1-10.

78. Inui K, Tran TD, Hoshiyama M, Kakigi R (2002) Preferential stimulation of Adelta fibers by intra-epidermal needle electrode in humans. Pain 96: 247252.

79. Inui K, Kakigi R (2012) Pain perception in humans: use of intraepidermal electrical stimulation. J Neurol Neurosurg Psychiatry 83: 551-556.

80. Mouraux A, Iannetti GD, Plaghki L (2010) Low intensity intra-epidermal electrical stimulation can activate $A \delta$-nociceptors selectively. Pain 150: 199207.

81. Kakigi R, Shibasaki $H$, Ikeda A (1989) Pain-related somatosensory evoked potentials following $\mathrm{CO}_{2}$ laser stimulation in man. Electroencephalogr Clin Neurophysiol 74: 139-146.

82. Lefaucheur JP, Ahdab R, Ayache SS, Lefaucheur-Ménard I, Rouie D, et al. (2012) Pain-related evoked potentials: a comparative study between electrical stimulation using a concentric planar electrode and laser stimulation using a $\mathrm{CO}_{2}$ laser. Neurophysiol Clin 42: 199-206.

83. Levitt $P$ (2003) Structural and functional maturation of the developing primate brain. J Pediatr 143: S35-S45.

84. Takahashi T (2005) Postsynaptic receptor mechanisms underlying developmental speeding of synaptic transmission. Neurosci Res 53: 229240.

85. Slater R, Worley A, Fabrizi L, Roberts S, Meek J, et al. (2010) Evoked potentials generated by noxious stimulation in the human infant brain. Eur Jain 14: 321-326.

86. Slater R, Cornelissen L, Fabrizi L, Patten D, Yoxen J, et al. (2010) Oral sucrose as an analgesic drug for procedural pain in newborn infants: a randomized controlled trial. Lancet 376: 1225-1232.

87. Fabrizi L, Verriotis M, Williams G, Lee A, Meek J, et al. (2016) Encoding of mechanical nociception differs in the adult and infant brain. Sci Rep 6: 28642.

88. Hartley C, Goksan S, Poorun R, Brotherhood K, Mellado GS, et al. (2015) The relationship between nociceptive brain activity, spinal reflex withdrawal and behaviour in newborn infants. Sci Rep 5: 12519.

89. Merkel SI, Voepel-Lewis T, Shayevitz JR, Malviya S (1997) The FLACC: behavioral scale for scoring postoperative pain in young children. Pediatr Nurs 23: 293-297.

90. Keck JF, Gerkensmeyer JE, Joyce BA, Schade JG (1996) Reliability and Validity of the Faces and Word Descriptor Scales to measure procedural pain. J Pediatr Nurs 11: 368-374.

91. Moultrie F, Slater R, Hartley C (2017) Improving the treatment of infant pain Curr Opin Support Palliat Care 11: 112-117

92. Gursul D, Goksan S, Hartley C, Mellado GS, Moultrie F, et al. (2018) Stroking modulates noxious-evoked brain activity in human infants. Curr Biol 28 : R1380-R1381.

93. Verriotis M, Fabrizi L, Lee A, Ledwidge S, Meek J, et al. (2015) Cortical activity evoked by inoculation needle prick in infants up to one-year old. Pain 156 : 222-230.

94. de Tommaso M, Ricci K, Montemurno A, Vecchio E (2017) Age-related changes in laser-evoked potentials following trigeminal and hand stimulation in healthy subjects. Eur J Pain 21: 1087-1097. 